\title{
LOGISTICS CENTRES DEVELOPMENT IN LATVIA
}

\author{
Igor Kabashkin \\ Transport and Telecommunication Institute, \\ Lomonosova 1, LV-1019 Riga, Latvia \\ E-mail:kiv@tsi.lv
}

Received 11 April 2007; accepted 10 September 2007

\begin{abstract}
In the situation where a large increase in trade and freight transport volumes in the Baltic Sea region (BSR) is expected and in which the BSR is facing a major economic restructuring, efforts to achieve more integrated and sustainable transport and communication links within the BSR are needed. One of these efforts is the development of logistics centres (LCs) and their networking, which will continue to have an impact on improving communication links, spatial planning practices and approaches, logistics chain development and the promotion of sustainable transport modes. These factors will reflect on logistics processes both in major gateway cities and in remote BSR areas.

The importance of logistics systems as a whole is not seen clearly enough. Logistics actors see that logistics operations are not appreciated as much as other fields of activity. In addition, logistics centres and the importance of logistics activities to the business life of areas and the employment rate should be brought up better.

In the paper main goal and tasks of national approach to LCs development are discussed. Strategic focus of new activities in this area is on the integration of various networks within and between logistics centres in order to improve and develop the quality of logistics networks as well as to spatially widen the networking activities.

The key objectives are to integrate the links between logistics centres, ports and other logistics operators in a functional and sustainable way, to promote spatial integration by creating sustainable and integrated approaches to spatial planning of logistics centres and transport infrastructure, to improve ICT-based networking and communication practices of the fields of transport and logistics and to increase the competence of logistics centres and associated actors by organising educational and training events.

The current activities include, for example, the creation of measures for transport networking and port modernisation, multimodal transport network strategies, integrated networks between ports, logistics centres and other operators, the better involvement of LCs in spatial planning and knowledge of the land use needs of the LCs, territorial impact assessments on selected transport corridors where logistics centres are located, the establishment of a common vision of the future spatial and environmental development along the transport corridors and LC-areas, the elimination of bottlenecks in port-hinterland-LC connections, the integration of telematics supported logistics networks based on identification and analysis of networks.
\end{abstract}

Keywords: logistics centres, telematics, virtual logistics portal.

\section{Logistical trends in the Baltic Sea region}

In the situation where a large increase in trade and freight transport volumes in the Baltic Sea region (BSR) is expected and in which the BSR is facing a major economic restructuring, efforts to achieve more integrated and sustainable transport and communication links within the BSR are needed. One of these efforts is the development of logistics centres (LCs) and their networking, which will continue to have an impact on improving communication links, spatial planning practices and approaches, logistics chain development and the promotion of sustainable transport modes.

The importance of logistics systems as a whole is not seen clearly enough. Logistics actors see that logistics operations are not appreciated as much as other fields of activity. In addition, logistics centres and the importance of logistics activities to the business life of areas and the employment rate should be brought up better [1].

In general, the planning process is seen to be too slow from both the logistics actors' and spatial planners' point of view. Obviously the procedure differs in each country as well as the time needed to proceed. Other barriers concerning LCs establishment and development could be concluded in four areas: support for the public sector, public-private partnership, financing and realisation.

The general political aim of regional economic development is often the driving force behind the creation of logistics centres. 


\section{Role and place of logistics centres in the Latvian national transport policy}

The section includes summary of interviews with transport policy makers, logistics operators, spatial planners in Latvia about the spatial planning need of logistics centres and about the state of co-operation between logistics operators and spatial planners in this question [2].

The main goal of interviews - identification vision of different actors involved in the process of planning and development of LC on real state and possible decisions in this area.

In the future it is planned to set up freight distribution centres in Riga, Ventspils, Liepaja, Rezekne, Daugavpils and at other principal transport junctions (Fig. 1).

It is regarded that one of the most important issues for peripheral regions development is the development of logistics and distribution centres focused on attracting freight from Asia and the Far East. Latvia can serve as a distribution centre for cargo from Asian countries (e.g. China, Korea) not only in the Baltic States but also with equally successful results in Russia and the CIS countries. But today the idea of logistics centre is at early stage of development in Latvia.

\subsection{General vision}

1. State spatial planners have not a vision on development of logistics centres.

2. Seaport city-regions are key nodes in the global logistics freight transportation network. The mari- time activities exploited at the seaport location may promote the regional economic growth of the surrounding area because of the circular and cumulative causation a central place is capable to give origin to. The most appropriate regions for logistics centres development are ports of Riga, Ventspils and Liepaja.

3. Transport policymakers and logistics operators both stress the necessity to build up an efficient transportation system by promoting the intermodality patterns through the establishment of distribution and inter-modal centres. The seaport cityregion should promote the settlement of such public logistics terminals at the local level in order to promote the local entrepreneurship, as well as to reduce the environmental impact of the freight transport within the urban area. The building of the inland logistics terminal at the more far hinterland locations should increase in efficiency the whole transport system because of the promotion of the inter-modality.

4. The three main goals of co-operation between actors, that are supposed to be achieved, can be summarised as the following: 1) to establish a more efficient logistics system; 2) to facilitate the implementation of advanced information systems; 3 ) to promote cooperative freight systems.

5. The LC has to be seen as a meeting point for both public and private logistics operators (Fig. 2). The consolidation of the urban logistics activities can be realised at this freight transport node of the

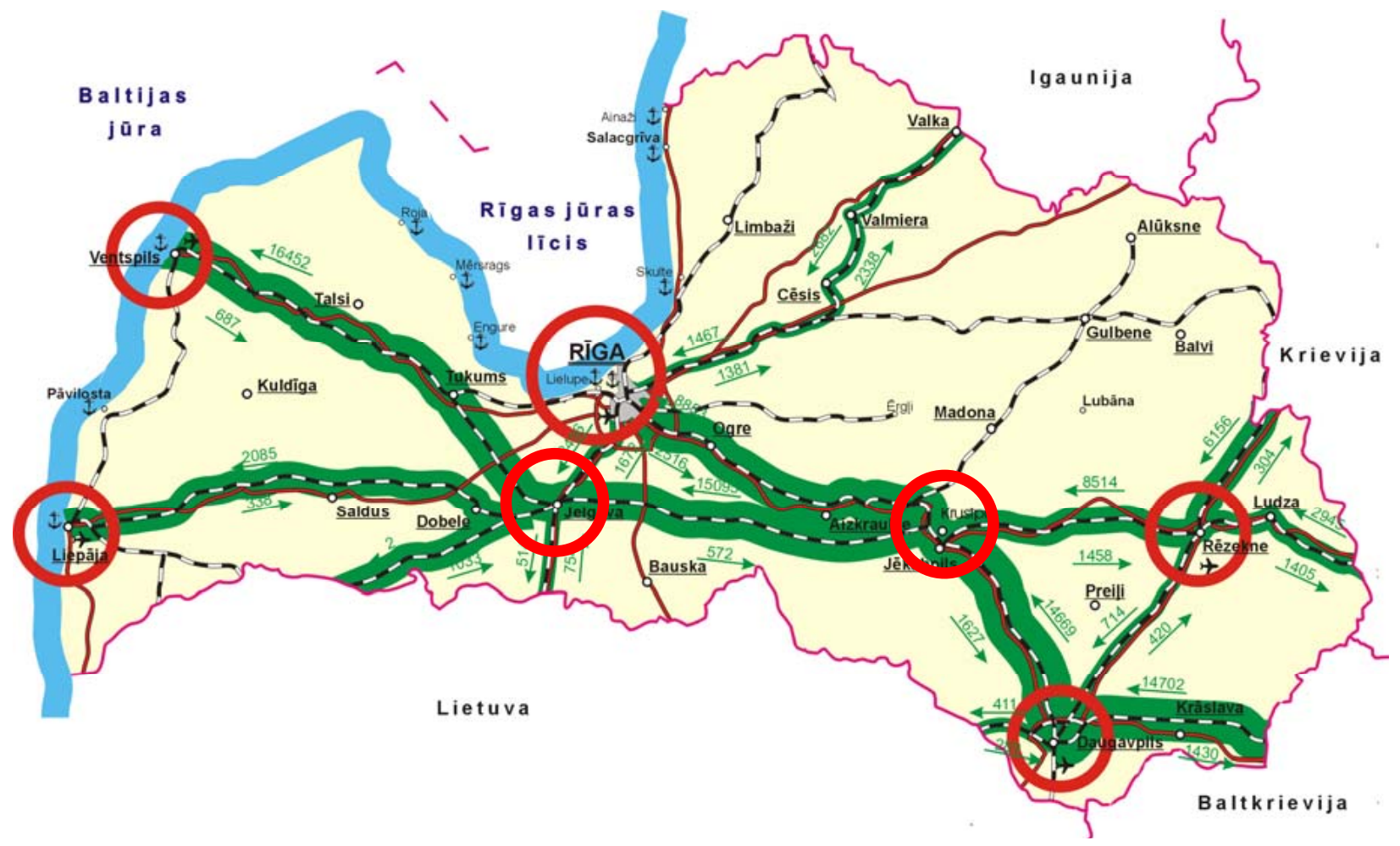

Fig. 1. Network of possible LCs in Latvia 
transportation network by the application of the most advanced information systems.

6. An efficient co-operative freight transportation system can be implemented at the LC location. This co-operative system enables a large number of shippers or freight carriers to share jointly a freight vehicles system, joint terminals, as well as common information systems in order to exploit the synergy effects the spatial agglomeration of the logistics operations spread out.

7. The individual economic agent should be able to reduce the costs for collecting and delivering goods due to the exploitation of the economics of space at the LC. The spatial agglomeration enables the cooperative performance of the logistics operations jointly with other entrepreneurs, as well as the supply to the customer of a level of services of better quality.

8. Through the establishment of a spatial multifunction cluster the entrepreneurship in the logistics transport sector may be promoted, and at the same time the negative externalities generated by the road transport modality may be reduced.

9. The establishment of public logistics terminals in the area surrounding a seaport city can be helpful for promoting the co-operative freight transport systems.

\subsection{The main problems of the logistics centres development} of LC:

There are two main problems in the development

- the optimal geographical location;

- the optimal spatial physical size of the LC.

The location choice among different potential sites has to evaluate the trade-off between transportation cost and facility cost. The facility cost is defined by the sum of the construction, maintenance, land and truck operation costs at the LC site.

The land price plays a major role when the potential nodal location is settled nearby the urban agglomeration. In this case, the lower transport costs the logistic operators had to bear for the pick-up/delivery activities between the LC and the urban centres might compensate in such a way the more expensive fixed investments necessary to bin the land, as well as for building the infrastructure.

The public planner should have the role to perform a macroeconomic decision about the more suitable geographical location and dimension of the LC. His aim is to minimise the total cost of the LC. It follows that the accessibility patterns are absolutely relevant.

The public planner has no influence at the microeconomic level of decision, when the distribution and assignment of the freight traffic is considered.

At a micro level, where the individual transport operator decides to use his own freight vehicle, the choice of making a stopping call at a certain LC rather than another is supposed to be determined by the behaviour of the single transport operator or company. At this level of choice the goal is to minimise the transport costs.

\subsection{Advanced information systems}

The improvement of advanced information systems is one of the most relevant instruments in order to achieve the rationalisation in the logistics activity. Planning in advance the routing and scheduling of the consignments may effectively improve the efficiency in the transport system.

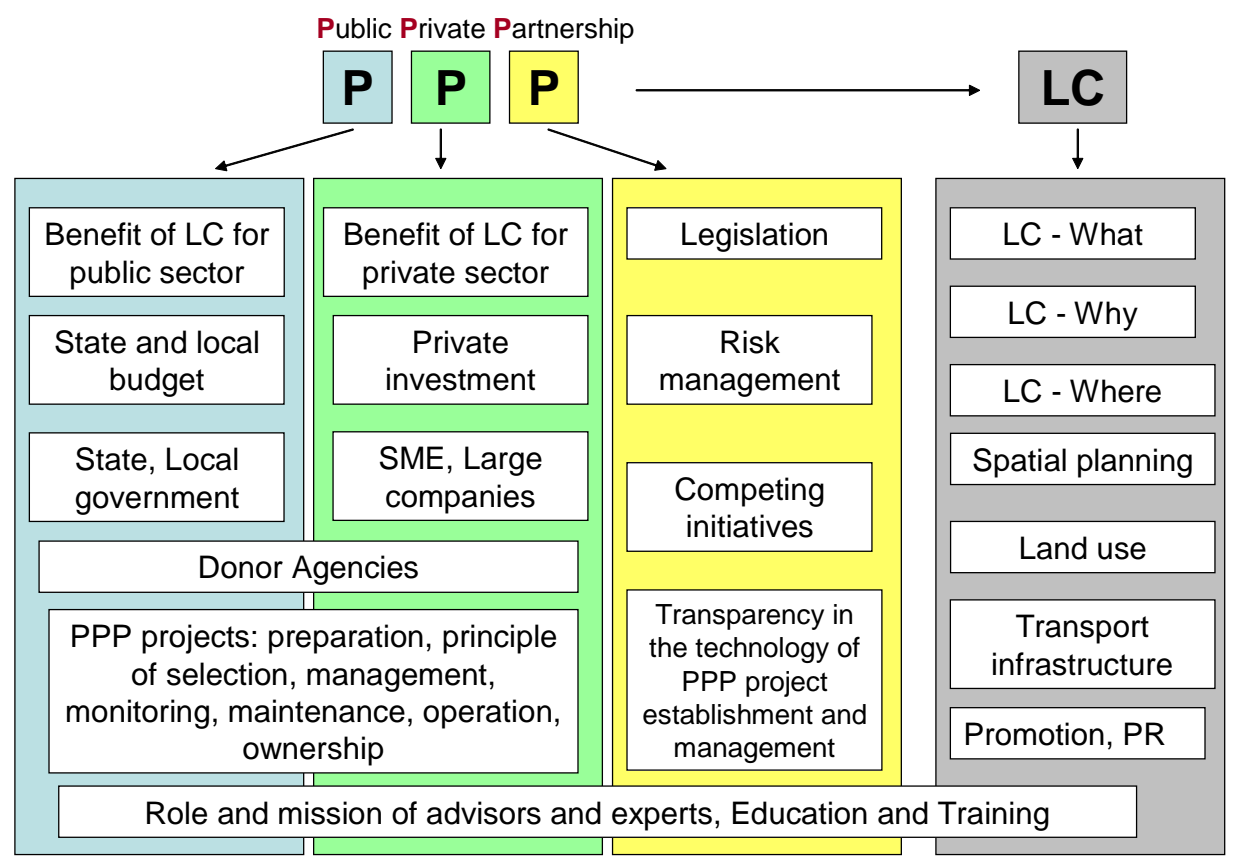

Fig. 2. The main tasks for creation of LC 
The most important findings beyond the particular ease are as follows:

- Large customers (shippers) require logistics partners (forwarders) to either accept paper input (primarily fax) or to subscribe to customer's choice of technology. Such customers are unlikely to reimburse their partners for related effort, the implementation thus has to bear sufficient saving potential for the forwarder.

- EDI data transmission and the relating process automation provide the basis for improvements of transport planning and execution.

- Port community systems provide the technical, managerial and business background to implement EDI systems.

- Linking only one additional exporter or importer in the hinterland may have very significant multiplication effects. The company may communicate with additional partners in the same and in other ports. Likewise the resident logistics partner has also been enabled to communicate with other hinterland partners.

- A success factor is the usage of standardised communication and messages. In transport EDI has the largest user base.

Computer based information systems in transportation chains have several advantages:

- Increased management options through tracking and tracing and improved quality control of own services and those of subcontractors;

- Outsourcing of transport services, but staying in control of logistics performance;

- Increased production-to-order orientation and better transparency of market demand and supply.

\subsection{Project "Multimodal virtual logistics centre"}

The overall objective of the "Multimodal Virtual Logistics Centre" (MVLC) is to create a virtual single point of entry to the telematics services relating to all modes of transport with Latvian neighbouring countries (Fig. 3).

The MVLC system will improve the integration of ports and railway into intermodal transport chains.

The main goals within the realisation of the MVLC system are the following [2]:

- to harmonise administrational procedures and make them easily usable throughout Latvia (e.g. by unifying the interfaces between shipping agents and ports);

- to establish a "virtual entry point" service for information in the port with a common interface no matter of the organizational partners behind, e.g. port operator, stevedore, port authority, harbour master, port community systems, etc.;

- to make available information supporting the operation of the whole intermodal chain accessible to (all) other partners in the chain; depending on their level of computerisation this can be done via combination of EDI and Web-based services.

This confirms that MVLC should not be thought of as a system but a continuous process of moving forward.

This progress should start from creating basic facilitating services (EDI-based) in the short term thus creating the base for more valued products and applications.

The activities presented in the project are oriented towards specifying the new transport concept and making the implementation plan for the new system to act as a "virtual logistics service center" in the region and providing state-of-the-art products and services to the transportation industry and its clients.

It is not possible to gain results in the whole area of port community telematics in short future, so the princi-

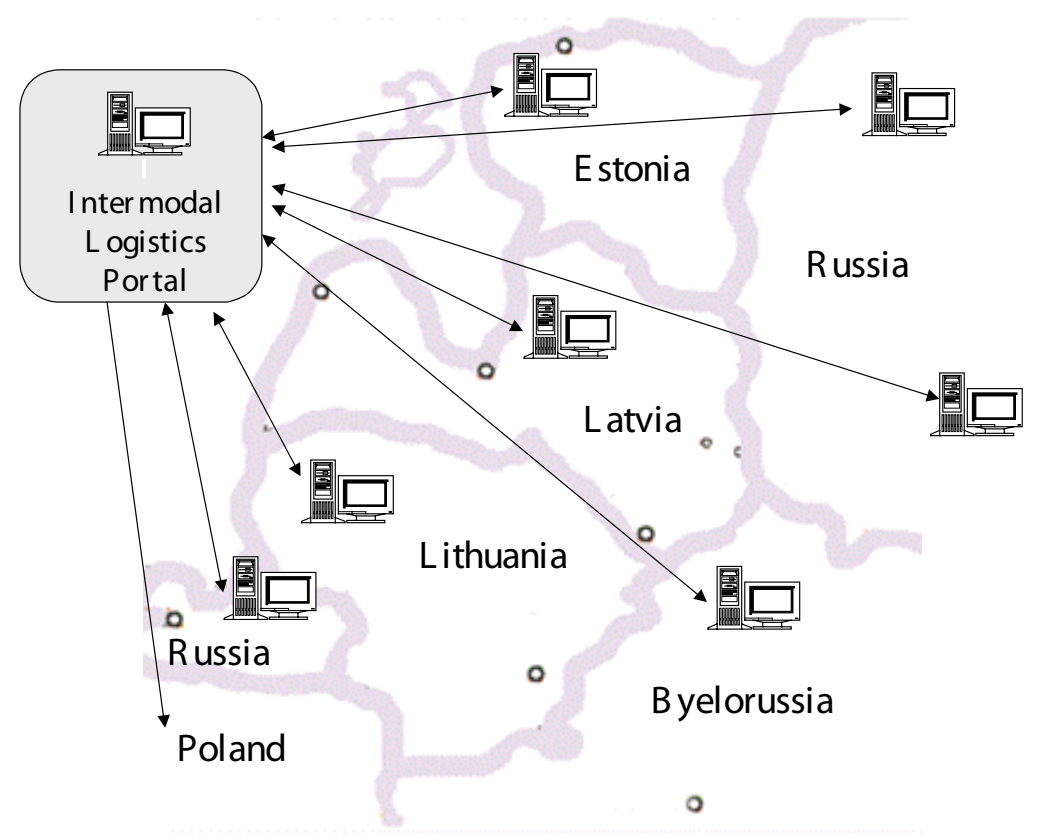

Fig. 3. Network of virtual LC 
ple of piloting has been accepted in MVLC. This means that a few most urgent areas have been identified as pilots for further studies or implementations.

These areas and pilot proposals are:

- Change of processes in two potential bottleneck areas of border crossing and railway co-operation including electronic exchange of cargo information. This will serve mainly the transit operations by rail.

- Establishment of a messaging service operation to facilitate the necessary messaging between parties.

- The idea of intermodal portal will serve as an Internet-based application providing marketing information on logistics, links to main services, operational links such as booking and many others.

The initial investment for all proposed projects will be used for:

- external work and consulting;

- establishment of a messaging EDI centre with all hardware and software components;

- definition of new process models for customs and railways concerning mainly border-crossing;

- construction of the first phase Intermodal Portal system (Fig. 4).

The objective of project is to realise the special technologies, which are already known but not in use on the corridor yet. The aim is to find out technologies or organizational aspects, which help to strengthen the competitiveness of the alternative traffic modes on the de- scribed corridor. The overall goal of project is to ensure competitiveness of European logistics by investing in the infrastructure and supporting services including information technology.

\section{Conclusions and recommendations}

Co-operation between the parties in a transport chain, between ports, regions and authorities can give concrete improvements to everyday practical problems and thus contribute to the goals of cohesion and economic development in the BSR. The results have been achieved in a highly competitive environment and indicate that there are areas for co-operation, which do not distort competition, but promote a sustainable transport system for the benefit of the society as well as the private players. Such areas are the following:

- Promotion of the use of IT among the port community and between the port and the world outside.

- Introducing IT in the business process is a complex issue affecting internal and external procedures, core business ideas and market positions. Building efficient IT relations between authorities and private organisations requires special attention. E-business development suggests that Internet will speed up the reorganisation of commercial relations and market behaviour. Apart from infrastructure, companies need some basic agreements on standards. The public sector on a

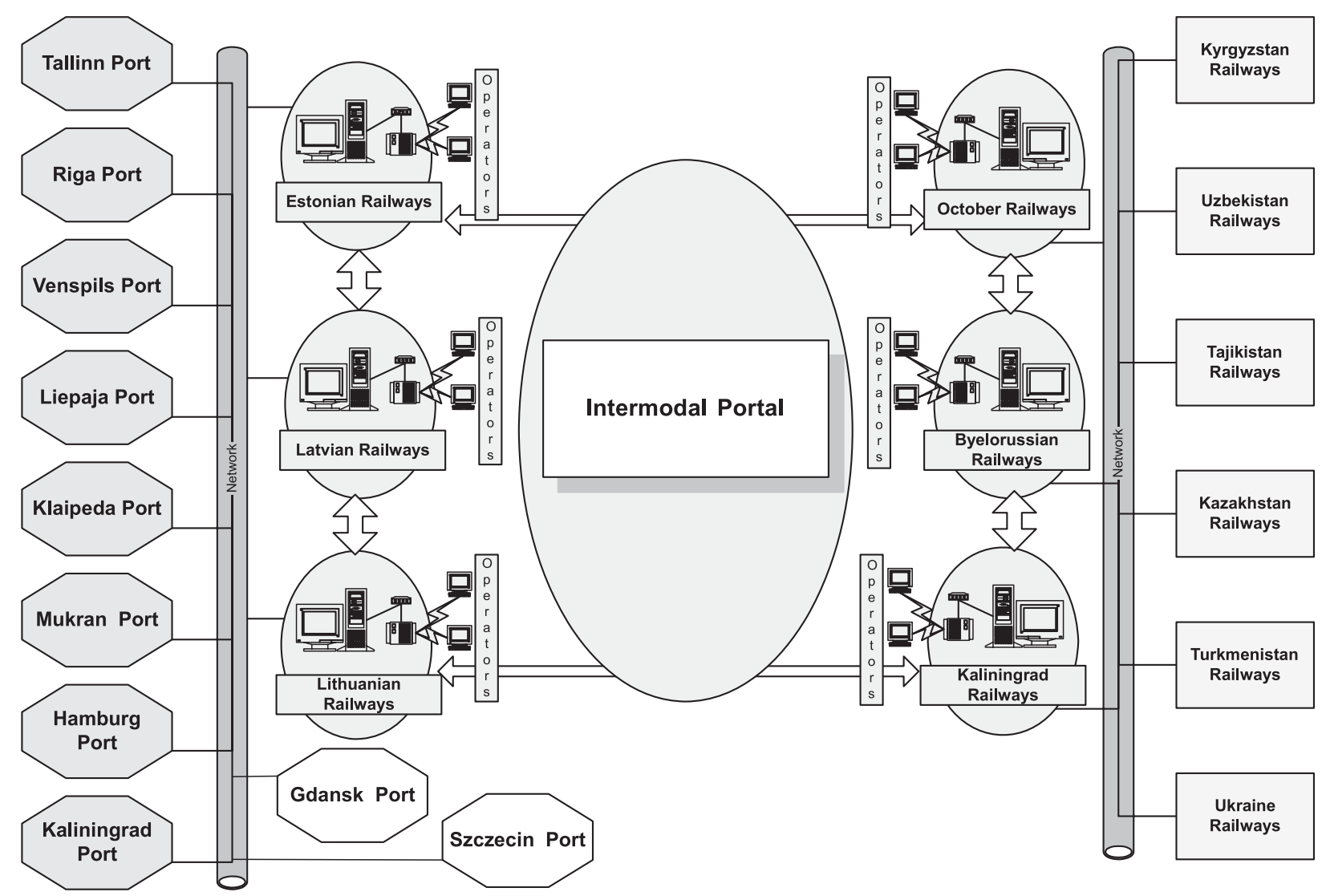

Fig. 4. Architecture of virtual LC network 
national, regional or local level can act as a catalyst in this process.

- Co-operation between customs and other authorities in specific transport corridors.

- Goodwill and mutual trust is a good basis for solving practical problems within an existing regulatory framework. Regional authorities along a transport corridor sector can together create the platform for such facilitation work. They can bring in all parties and moderate the work of creating a common understanding of the problem and hopefully also finding a practical solution.

- Regional co-operation between public bodies and private companies in order to understand spatial needs based on the assessment of long-term commercial trends for waterborne transport and other factors affecting future transport demand.

- Implementing new networks between transport companies, scientific organisations and port cities.

It is not surprising, that logistics centres tend to be located near the transport corridors. Access to all transport modes is vital for the success of logistics centres. The closeness to ports and sea transportation is natural for establishing a logistics centre in Latvia.

Based on corridor analysis, it seems there are many possibilities for new logistics centres:

- the railway hubs in Rezekne, Daugavpils and Jelgava;

- the important port cities of Riga, Ventspils and Liepaja.

The success of these ports and logistics development projects depends strongly on the development of transit traffic.

Using waterborne transport implies to also use other modes. This means that integrated transport concepts must be developed providing efficient interfaces between transportation means, organisations and authorities. Computer based communication and information systems must be used to provide the necessary management and business support.

The harbour will form a core area in a wider concept of activities in the adjacent area of the city. Such activities might be many kinds of international, national and local commercial activities, logistics firms, consulting and transport services, etc. Together with the harbour itself, this will form a logistics centre in the region as well as a transport hub (multimodal centre).

\section{References}

1. PERÄLÄ, H. Logistics centres, transport corridors and networks in the Northern and Eastern BSR: Present planning challenges. In Proceedings of the Final NeLoC Conference, January 15th, 2004, Turku, Finland.

2. KABASHKIN, I. Trends of transport and logistics development in Latvia: Infrastructure, logistics centres and supply-chain management. In Proceedings of the International Conference "Eastern Europe - New Logistics Resources". International Federation of Warehousing and Logistics Associations. May 29-June 02, 2006, Riga Latvia. IFWLA, Riga, p. 22-34. 